\title{
Announcements of Sanctions and the Russian Equity Market: An Event Study Approach
}

\author{
Pavel Dovbnya, New Economic School ${ }^{1}$ \\ pdovbnya@nes.ru
}

The research question raised in this paper is an investigation of the effect of the announcement of US and EU sanctions on the stock returns of the targeted companies listed on the Moscow Exchange. The strategy for identification is based on firm-specific and multivariate short-term event studies. Firm-specific event study of eight sanctions that targeted 14 entities at different times results in a statistically significant $-5.4 \%$ estimate of the expected cumulative abnormal return within a window of seven trading days.

Keywords: sanctions, Russian equity market, event studies, abnormal returns, $M O E X$

JEL Codes: G14, F51
Citation: Dovbnya P. (2020). Announcements of Sanctions and the Russian Equity Market: An Event Study Approach. Russian Journal of Money and Finance, 79(1), pp. 74-92.

doi: $10.31477 /$ rjmf.202001.74

\section{Introduction}

The question of the effectiveness of the Western sanctions against Russia remains unsolved. Both in the US and Russia there is still a heated debate over this issue, which makes a study of sanctions relevant to the discussion of public policy. The research question raised in this paper is an investigation of the effect of the announcements of US and EU sanctions on the stock returns of the targeted companies listed on the Moscow Exchange.

The identification strategy is based on short-term event studies. Event study methodology is designed to identify the short-term average cumulative impact of an event on the equity returns of the public companies that were directly or indirectly affected by the event. In the case of sanctions, an important division arises. On the one hand, an announcement of sanctions is a type of

\footnotetext{
${ }^{1}$ The author is a winner of the 2019 Economic Research Competition organised by the Bank of Russia and the Russian Journal of Money and Finance for students and postgraduates.
} 
announcement in and of itself. Thus, it should be studied across events. On the other hand, due to the idiosyncratic nature of specific sanctions, their announcements may be perceived as separate events which should be studied separately. Special approaches exist for each of these two situations: firm-specific event studies, for analysis across events, and multivariate event studies, for the analysis of particular events. A firm-specific event study is designed to answer the question: what is the expected pattern of cumulative abnormal returns of a company affected by a typical announcement of this particular type of event (announcement of sanctions)? It estimates the expectation of the cumulative abnormal return path conditional on the event window around a typical announcement. In turn, the question raised by a multivariate event study is different: what is the expected pattern of cumulative abnormal returns of a company affected by the event under consideration? It estimates the expected cumulative abnormal return path conditional on a particular event. For more information about these methods, see Section 4 and Appendices B and C.

In this work, the firm-specific event study method is applied to a set of eight sanction packages which, among other things, targeted either publicly traded Russian companies themselves or their subsidiaries, CEOs, or major shareholders. The multivariate event studies are used to disentangle the effect of inclusion in the US Office of Foreign Assets Control's (OCAF) ${ }^{2}$ Sectoral Sanctions Identifications (SSI) and Specially Designated Nationals (SDN) lists by investigating the two most extensive announcements of sanctions: (1) the inclusion of eight exchange-listed companies in the SSI list on 12 September 2014 and (2) the inclusion of six exchange-listed companies in the SDN list on 6 April 2018. For more information on these types of sanctions and the announcements, see Section 3.

The firm-specific event study demonstrates that, on average, the announcement of the imposition of sanctions that target a Russian public company has a negative impact on its equity returns. The average effect is measured as the estimate of the expected cumulative abnormal return within a window of seven trading days after a sanction announcement and amounts to $-5.4 \%$. The multivariate event study analysis of the two most extensive sanctions imposed by the US on the Russian economy - one on 12 September 2014 and the other on 6 April 2018 - shows that the effect of the announcement of the former was statistically equal to zero, whereas for the latter, estimates of the expected cumulative abnormal return already on the 5th day after the announcement are steadily around $-20 \%$.

\footnotetext{
2 The Office of Foreign Assets Control (OFAC) is a special agency of the US Treasury Department that develops, administers and enforces all of the US sanctions. See https://www.treasury.gov/resourcecenter/sanctions/sdn-list/pages/ssi_list.aspx for the SSI list, and https:/www.treasury.gov/resourcecenter/sanctions/sdn-list/Pages/default.aspx for the SDN list
} 
The limitations of the present study naturally include the small number of events being considered. There were only 8 sanction packages announced after March 2014 which, among other things, targeted Russian public companies. Moreover, only two of these sanction packages are extensive enough to be analysed in the framework of multivariate event studies. Nevertheless, even with the small number of events, the results are statistically robust, which means that one can draw some basic, though cautious, conclusions about the effectiveness of sanctions against Russia.

The rest of the paper is organized as follows. Section 2 provides a review of the literature on the topic of sanctions both in general and in the case of Russia specifically. Section 3 describes the data used in the event study analysis: the market data used in the regressions and the sanctions' events data set under consideration. A brief discussion of the methodology implemented is presented in Section 4. The main results of the event study are described in Section 5. Section 6 concludes the paper. The Appendix includes the broad presentation of the results of the event study in the form of graphs and tables as well as a complete description of all the mathematics that work behind the event study methods used in the work.

\section{Literature overview}

The literature on economic sanctions is diverse and can be divided into two broad groups: monographs and scientific articles. A comprehensive history of economic sanctions since World War I written by Hufbauer et al. (1990) demonstrates the complexity of sanctions as an economic phenomenon and that every instance requires its own approach when analysed. Zarate (2013) is a prominent monograph written by the former Deputy National Security advisor about the emergence, establishment and organisation of the US Treasury's international activity in the field of economic sanctions.

Scientific articles cover both theoretical and empirical questions. While empirical articles seek to answer questions about the effectiveness of sanctions and their effects on the targeted entities, theoretical papers focus on their microfoundations. Galtung (1967) was the first to perform comprehensive analysis of a particular case of sanctions - the British oil embargo against Rhodesia - from both theoretical and empirical point of view, in order to determine whether these sanctions were effective. Kirshner (1997) introduces a microeconomic model of sanctions trying to answer the question of how sanctions work.

This paper contributes to the literature on the sanctions against Russia since March 2014 and their impact on the Russian economy (and the Russian financial market in particular). Gurvich and Prilepskiy (2016) investigate the effect of the Western financial sanctions on the foreign funding of the sanctioned Russian state-controlled banks and the oil, gas and arms 
companies: the authors estimate the potential loss from sanctions at USD 280 billion in gross capital inflow over 2014-2017, but do not address the issue of identification. Nivorozhkin and Castagneto-Gissey (2016) study the dynamic relationship between the Russian and the global equity markets after the outbreak of the Ukrainian crisis in 2014. They find a considerable decrease in synchronicity between the markets, reflected by a significant decrease in the cross-correlation of market returns. Naidenova and Novikova (2018) use standard firm-specific event studies to detect the effect of the announcement of sanctions on Russian public companies' stock prices. However, their pool of events includes diplomatic, personal, economic and other types of sanctions in addition to sanctions targeting public companies. Moreover, they look at the stock returns of all major Russian public companies, regardless of whether a company was targeted by sanctions or not. This approach may potentially introduce additional noise to the results. In contrast, in my research I focus specifically on sanctions targeting companies listed on the Moscow Exchange and consider the stock returns only of those companies.

Using cointegrated vector autoregression (VAR) models, Dreger et al. (2016) compare the relative impact of the drop in oil prices and the imposition of sanctions on the fluctuations of the Russian ruble. They construct a composite index of sanctions and estimate the VAR model. Their main result is that most of the depreciation of the ruble is explained by the decline in oil prices, whereas the effect of sanctions is hardly significant. A similar index is used in Kholodilin and Netšunajev (2019) as the main component of a structural VAR model aimed at separating the long-run effects of the shock of sanctions and the oil price shock on the real sector of the Russian economy. The authors do not find evidence supporting the hypothesis that the slowdown in Russian GDP growth was caused by sanctions.

Finally, Ankudinov et al. (2017) perform a statistical comparative analysis of extreme movements (heavy-tailedness) in the returns of Russian stock indices before and after the imposition of sanctions. The breakpoint in their analysis is March 2014. Despite the fact that the authors detect structural breaks in heavy-tailedness for some Russian indices (Metals and Mining and Finance MOEX indices), they emphasize that the effect cannot be directly linked to the announcement of sanctions, since there was a significant contemporaneous drop in oil prices in the summer of 2014 .

Identification of the long-run effects is challenging, because the Russian financial markets depend heavily on global economic trends. The main goal of this paper is to contribute to the broad debate about the effectiveness of the sanctions against Russia by estimating their short-run effect on the equity returns of the targeted public companies. This approach allows the more accurate detection of the effect of sanctions, but it is silent on their long-run effects. 


\section{Data description}

\subsection{Moscow Exchange data set}

The official Moscow Exchange data set of all trades and best orders (type $\mathrm{B}^{3}$ ) on the securities market (stocks and bonds) is the main source of data used in the estimation of parameters.

The data set covers the period from 6 January 2014 to 31 July 2018. For each trading day, it includes the ticker symbol (the security's code), price, an indicator column that shows whether this price is the new best bid, new best ask or transaction price, time (down to microseconds) and volume. There are two major advantages of this data set that are important in the context of the further analysis. First, the data set is provided by the Moscow Exchange itself, which does not raise questions about its accuracy or credibility. Second, in contrast to end-of-day market data, type B intra-day data allows for the computation of volume-weighted prices. The use of last-3-minute, volume-weighted transaction prices instead of standard end-of-day transaction prices potentially leads to a more accurate calculation of daily returns. This becomes especially important in the analysis of volatile and high-volume trading periods.

When it comes to the estimation of the market model, for the purposes of a robustness check the daily returns of two indices are used: the MOEX Russia Index (IMOEX) and the MSCI Emerging Markets index (MSCI EM). The IMOEX is the major free-float index calculated by the Moscow Exchange on the basis of the most liquid stocks (depending on many factors, the average number of stocks is 45). The MSCI EM is a free-float index that covers the equity markets of 24 developing countries, including Russia. The advantage of this index over the IMOEX in the analysis is that the Russian equity market does not constitute a considerable part of the total market capitalisation of the MSCI EM, which makes the returns of the index less correlated with the returns of largecap Russian stocks. This feature allows more accurate detection and estimation of abnormal returns on Russian stocks, which is especially important in cases of companies targeted by sanctions, since the stocks of these companies are among the most liquid on the Moscow Exchange. An important point in working with the MSCI EM is that this index is denominated in dollars, whereas Russian stock prices are denominated in rubles. Therefore, the MSCI series was first converted to rubles according to the daily RUB/USD exchange rate, and only then were the rates of return calculated. The IMOEX daily time series was downloaded from the official Moscow Exchange website, whereas the data on the MSCI EM were downloaded from Thomson Reuters.

\footnotetext{
${ }^{3}$ The Moscow Exchange has three types of data: type A stands for the full limit order book, type B stands for the top of the book and type C for the end-of-day data. See Market Data description section on www.moex.com/en
} 


\subsection{Sanction-related stocks}

I first created a list that would include all of the major sanctions introduced and their classification. For this purpose, I made a complete list of all the sanctions imposed on Russia by the US and the EU over the period from March 2014 to November 2018 (see Appendix F). This list also includes all the counter-sanctions imposed by Russia on the US and the EU.

There was no existing comprehensive record of sanctions imposed at the time this paper was written (at least in free sources). The list was prepared manually on the basis of news articles from the RBC and RIA News agencies, and also on the basis of official US Treasury and EU announcements. The sanctions against Russia can be classified into the following five categories: diplomatic (e.g., the expulsion of diplomats), personal (targeting specific persons), corporate (targeting particular companies), economic (e.g., a ban on the export of technologies to a specific Russian industry) and extending (sanctions that extend the enforcement of previous sanctions). The sanctions can also be classified according to the reason for their imposition: Ukraine-, Syria-, Skripal- or US elections-related.

In this paper, I focus on the effect of the announcement of sanctions on the returns of stocks on the Moscow Exchange. In order to make the results more specific, I study only sanctions that directly affect companies listed on the Moscow Exchange. I consider a set of sanctions that includes personal, corporate and economic sanctions, and a set of companies that includes those targeted by some of these sanctions and whose stocks were traded on the Moscow Exchange at that time. Based on the sanctions list described above, the record of the Moscow Exchange codes and the complete list of all the companies under sanctions prepared by $\mathrm{RBC}^{4}$ (as of December 2018), I compiled a list of the sanctions that, among other things, targeted either publicly-traded Russian companies themselves or their subsidiaries, CEOs, or major shareholders. The list of sanctions and companies is presented in Table 1. This set of companies and sanctions will be the focus of further analysis.

The sanctions under consideration can be divided into two groups. The first group of sanctions adds the target to the OFAC's SSI list. The second group of sanctions adds the target to the OFAC's SDN list. The SDN list is the most important of the OFAC's sanction lists and is designed to target any person or company in the world. The SSI list was created in July 2014 specifically for the Ukraine-related sanctions against Russia. The key difference between these lists is that the SDN list prohibits US citizens from doing any kind of business with the persons/entities included in it, and also requires the freezing of all assets belonging to the target, while the SSI list allows the elaboration of partial sanctions

\footnotetext{
${ }^{4}$ See https://s0.rbk.ru/v6_top_pics/media/file/1/59/755452933522591.pdf
} 
that restrict connections with the target only in particular areas. Both lists follow the so-called ' 50 Percent Rule', which says that if a targeted person has more than a 50 percent stake in some company, then the company is automatically added to the list. That is why Polyus - a public company controlled by S.A. Kerimov is included in the data set (8) of Table 1.

Basic intuition and interesting insights can be obtained from simple graphical analysis. Figure 1 shows that normalized stock prices in the 14-day event windows of the announcement of sanctions (seven trading days before the announcement and seven trading days after) generally have a downward pattern. Two sanctions stand in the sharp contrast to the others: those of 12 September 2014 and 6 April 2018. These sanctions are the most extensive: they target six and eight public companies respectively.

Yet, the sanctions of 12 September 2014 and 6 April 2018 differ considerably. First, on 12 September 2014, the companies were added to the SSI list, whereas on 6 April 2018 the companies were added to the SDN list. Second, Figure 1 demonstrates that there is no clear pattern in the time series of prices for the event window around 12 September 2014. In contrast, the practically unchanging path of prices before 6 April 2018 is followed by a dramatic drop on 6 and 9 April (6 April was a Friday) for four of the six companies.

Figure 8 and Figure 9 in Appendix A show that the daily trading volume and daily realised volatility for stocks in each of the event windows exhibit patterns similar to that described above.

In general, the visualized data show the intuitively expected result: on average, it seems that sanctions are accompanied by a drop in stock prices, increased trading volume and volatility of returns. Yet, the magnitudes and patterns are clearly different, especially in the cases of sanction packages of 12 September 2014 and 6 April 2018. Such different behaviour can probably be explained by two factors: (1) whether the sanction corresponds to inclusion in the SSI or SDN list; and (2), whether the sanction was expected by the market or not. While the first factor seems to be plausible enough, since a restriction of financing is not the same as a prohibition of doing business, the second factor is likely to be less important: analysis of the news in the weeks prior to 12 September 2014 and 6 April 2018 shows that in both cases there was information about the upcoming sanctions, but there was no information about the targeted companies. ${ }^{5}$ Nevertheless, in order to draw robust and credible scientific conclusions about the reaction of the market to the announcement of sanctions, one must apply a suitable econometric methodology and properly adjust it for risks.

\footnotetext{
${ }^{5}$ See, for example, https://www.nytimes.com/2014/09/05/world/as-nato-meets-ukraine-conflictholds-center-stage.html. In addition, see https://www.reuters.com/article/us-usa-russia-sanctions/ u-s-plans-to- sanction-russian-oligarchs-this-week-sources-idUSKCN1HB34U
} 
Figure 1. Normalised prices of stocks in the event window of a sanction announcement

(1) 28 Apr 2014

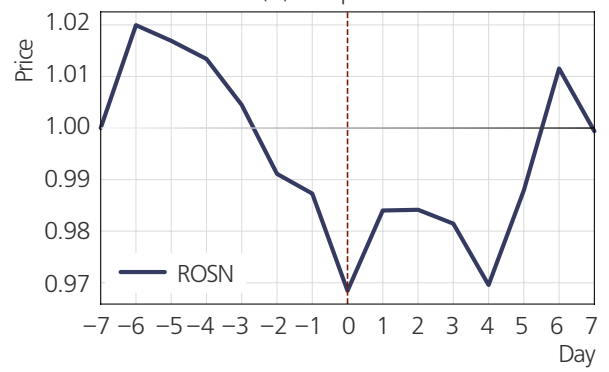

(3) 30 July 2014

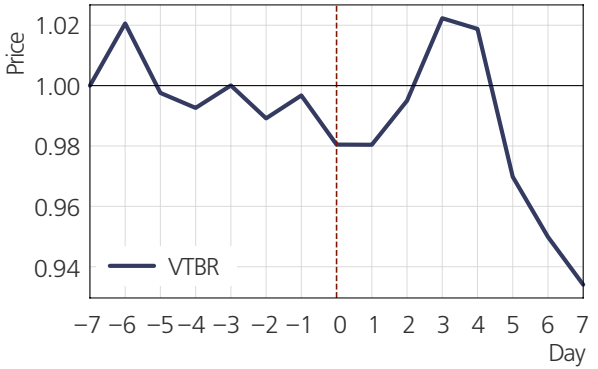

(5) 23 Sept 2015

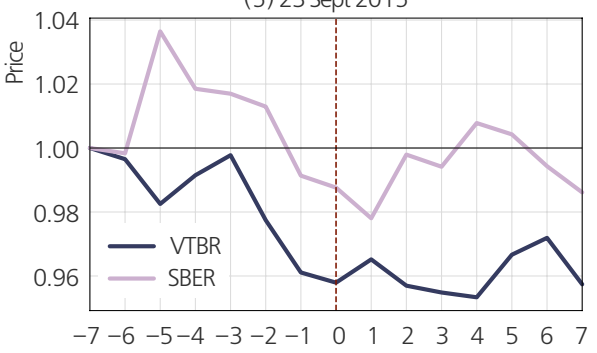

(7) $26 \operatorname{Jan} 2018$

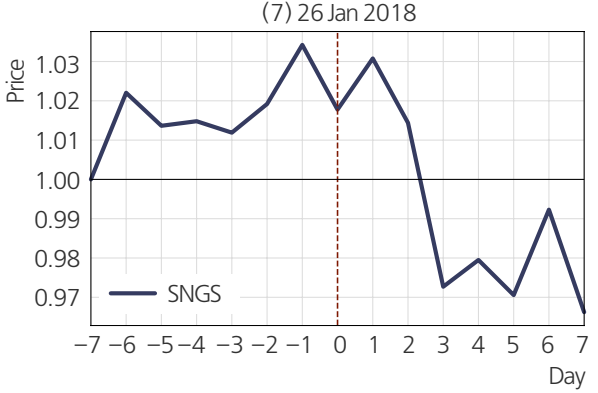

(2) 17 July 2014

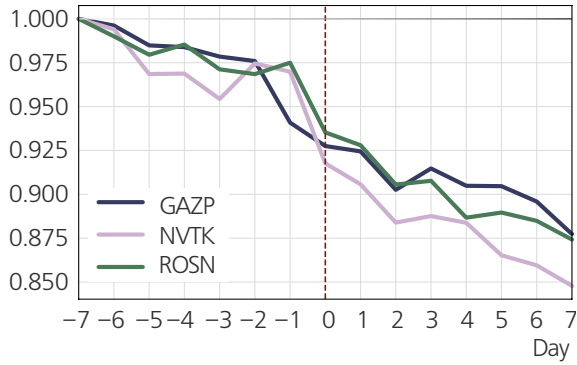

(4) 12 Sept 2014

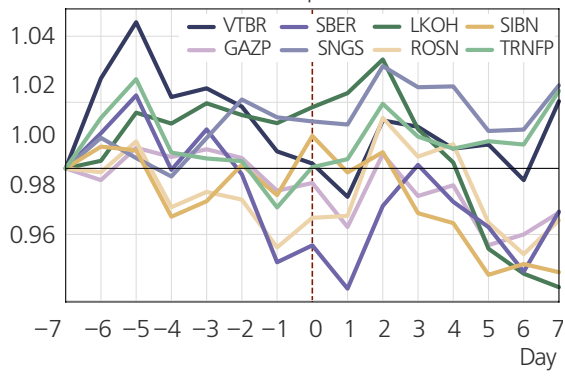

(6) 2 Sept 2016

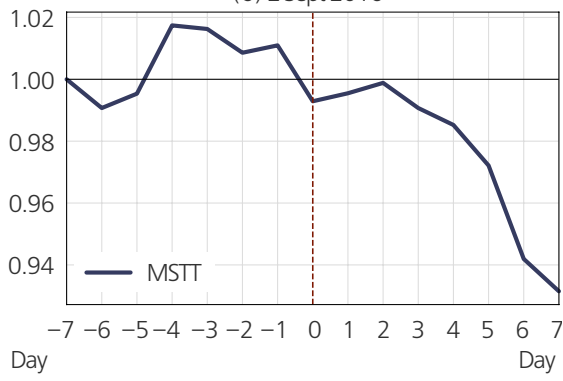

(8) 6 Apr 2018

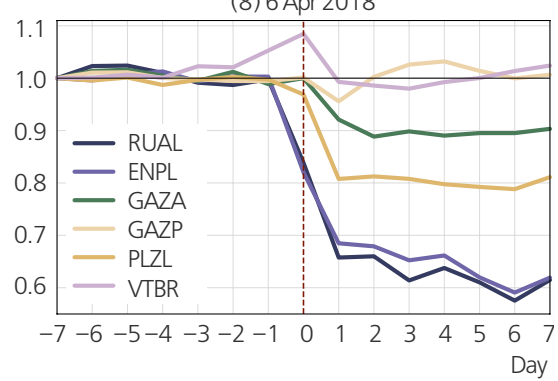

Source: author's calculations 
Table 1. List of sanctions imposed on Moscow Exchange-listed companies

\begin{tabular}{llll} 
№ Date/Country & Codes & Description/Link \\
\hline (1) 28 April 2014, US & ROSN & $\begin{array}{l}\text { The company's CEO, I.I. Sechin, was added to the OFAC's SDN List. } \\
\text { https://www.treasury.gov/resource-center/sanctions/ofac- } \\
\text { enforcement/pages/20140428.aspx }\end{array}$ \\
\hline (2) 17 July 2014, US & $\begin{array}{l}\text { GAZP, } \\
\text { NVTK, } \\
\text { ROSN }\end{array}$ & $\begin{array}{l}\text { Gazprombank (35\% owned by GAZP), ROSN and NVTK were } \\
\text { restricted in their access to 90-day+ maturity US financing (SSI list). } \\
\text { https://www.treasury.gov/press-center/press-releases/pages/ } \\
\text { jl2572.aspx }\end{array}$ \\
\hline (3) 30 July 2014, US & VTBR & $\begin{array}{l}\text { VTBR and the Bank of Moscow (having been taken over by VTBR) } \\
\text { were restricted in their access to 90-day+ maturity US financing (SSI). } \\
\text { https://www.treasury.gov/resource-center/sanctions/OFAC- } \\
\text { Enforcement/Pages/20140729.aspx }\end{array}$ \\
& &
\end{tabular}

(4) 12 Sept 2014, US/EU GAZP, (1) Gazprombank, SBER and VTBR were restricted in their access to $\mathrm{LKOH}, \quad 30$-day+ maturity financing from the US (SSI list);

ROSN, (2) US entities were prohibited to export goods, services, or SBER, technology to GAZP, LKOH, ROSN, SIBN and TRNFP in support of SIBN, exploration for or production of Russian deepwater, Arctic offshore, or SNGS, shale projects that have the potential to produce oil;

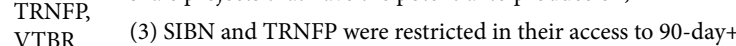
VTBR maturity US financing (SSI list);

(4) SIBN, ROSN and TRNFP were restricted in their access to 90-day+ maturity EU financing.

https://www.treasury.gov/press-center/press-releases/Pages/ j12629.aspx

https://eur-lex.europa.eu/legal-content/GA/ TXT/?uri=CELEX:32014R0960

(5) 23 Sept 2015, U.S SBER, A number of SBER and VTBR subsidiaries were added to the OFAC's VTBR SSI list.

https://www.treasury.gov/resource-center/sanctions/OFACEnforcement/Pages/20151222.aspx

(6) 2 Sept 2016, US MSTT MSTT was added to the OFAC's SDN list.

https://www.treasury.gov/resource-center/sanctions/OFAC-

Enforcement/Pages/20160901.aspx

(7) 26 Jan 2018, US

SNGS

A number of SNGS subsidiaries were added to the OFAC's SSI list. https://www.treasury.gov/resource-center/sanctions/OFACEnforcement/Pages/20180126.aspx

(8) 6 April 2018, US

ENPL GAZA, GAZP,

PLZL,

RUAL,

VTBR
(1) The CEOs of GAZP, RUAL and VTRB - A.B. Miller, O.V. Deripaska, A.L. Kostin respectively - were added to the OFAC's SDN List;

(2) The major shareholder of PLZL - S.A. Kerimov was added to the OFAC's SDN List;

(3) ENPL, GAZA and RUAL were added to the OFAC's SDN List. https://www.treasury.gov/resource-center/sanctions/OFACEnforcement/Pages/20180406.aspx

Note: links to the official US Treasury and EU announcements are provided. MOEX ordinary shares' codes stand for: ROSN - Rosneft, GAZP - Gazprom, NVTK - Novatek, VTBR - VTB Bank, LKOH - Lukoil, SBER - Sberbank, SIBN - Gazprom Neft, SNGS - Surgutneftegaz, TRNFP - Transneft, MSTT - Mostotrest, ENPL - EN+, GAZA GAZ Group, PLZL - Polyus, RUAL - Rusal. 


\section{Methodology}

In financial econometrics, the classic method to determine the effect of a news announcement on the returns of stocks is the event study approach. Its major advantage is that it solves the issue of identification: given that there is no confounding event prior to the announcement of a sanction, it guarantees that the effect is correctly identified. However, it also has a significant drawback: the bigger the event window is, the higher the variance of the effect studied. In other words, event studies perform well only over short horizons. The main goal of any event study is to estimate the effect of a specific type of announcement (or of some particular announcement) on stock returns by estimating the cumulative average abnormal returns (CAAR) in the event window around the announcement.

There is an important peculiarity of the framework we are working in. On the one hand, sanction announcement is a type of announcement by itself. Thus, it should be studied across events. On the other hand, due to the differences between the sanctions described above, sanction announcements can be perceived as events that should be studied separately. In the context of event studies, a special approach exists for each of these two situations.

First, firm-specific event study - the standard - is designed to identify the effect of a particular type of shock, such as earnings announcements or announcements about some macroeconomic indicators. In other words, it addresses the question: What is the expected pattern of cumulative abnormal returns of a company affected by a typical announcement of this particular type of event (in our case, the announcement of sanctions)? Formally speaking, it estimates the expectation of the cumulative abnormal return conditional on the event window around the typical announcement. The main requirement of this framework is that the events in the data set are gathered in such a way that there is no overlap between the event windows. This requirement asserts that there is no correlation between the abnormal returns of stocks (clustering), a problem that firm-specific event studies are not designed to address. In cases of significant cross-correlation of abnormal returns, the variance of CAARs will be estimated incorrectly, which will lead to inaccurate confidence intervals (CIs). For more information about the methodology of firm-specific event studies, see Chapter 4 in Campbell et al. (1997), and also Kothari and Warner (2007).

Second, the approach used to analyse the effect of a particular announcement is called multivariate event study. It is designed to tackle the problem of crosssectional correlation between abnormal returns, allowing the identification of the effect of an event that had a simultaneous impact on a number of firms. However, in contrast to firm-specific event studies, this approach cannot deal with different event windows at the same time. In our case, this drawback makes the approach applicable only to the analysis of sanctions that were announced 
either on 12 September 2014 or on 6 April 2018. The question addressed by a multivariate event study is: What is the expected pattern of cumulative abnormal returns of a company affected by the event under consideration?

Fama et al. (1969) were the first to introduce event study methodology as a tool of financial econometrics. Multivariate event studies were first implemented by Binder (1985). However, the author notes that the distribution of test statistics in multivariate event studies is not well approximated by the asymptotic approach, since the assumption of independent and identically distributed error terms is often violated in the context of stock returns. This problem gave rise to the application of bootstrapping in multivariate event studies. In case the test statistic is pivotized (i.e., its asymptotic distribution does not depend on the parameters), bootstrapping ensures asymptotic refinement, that is, better approximation of the actual distribution of test statistic. For the purposes of robustness, I use bootstrapping together with an asymptotic approach in conducting multivariate event studies. For the general bootstrapping methodology, see Anatolyev (2007). The application of bootstrapping in multivariate event studies is developed in Chou (2004) and Hein and Westfall (2004), and then revised in Lefebvre (2007). Note that the main difference between the general bootstrapping approach and the one that is used in event studies is that the latter does not account for the recentering of bootstrap statistics, since the bootstrap samples are constructed in such a way that there is no event at all.

A complete and self-contained description of the econometric, statistical and bootstrap methodology used in this work is given in Appendix B and Appendix C. All estimates are implemented by a Python code. In Python, the following packages were used: NumPy, Pandas, SciPy and Matplotlib.

\section{Results}

\subsection{Firm-specific event studies}

The core problem is that there are only 8 observations of events in Table 1 . There are $1 \cdot 3 \cdot 1 \cdot 8 \cdot 2 \cdot 1 \cdot 1 \cdot 6=288$ possible samples of companies such that the event windows do not overlap (i.e. one company per announcement). Figure 2 clearly demonstrates that the resulting CAARs and their significance depend crucially on the choice of companies in the sample.

The main obstacle in conducting a firm-specific event study is the choice of companies to be included in the sample. To make the result robust to the sample choice, one can conduct an event study for each of the 288 possible combinations of companies and average the results. From the standpoint of formal mathematical statistics, this approach is incorrect, because the CIs intervals for the 'average' CAAR are not the averaged CIs of the resulting CAARs. Nevertheless, this approach gives an intuitive result about the average 


\section{Figure 2. Firm-specific event studies for different combinations of companies}
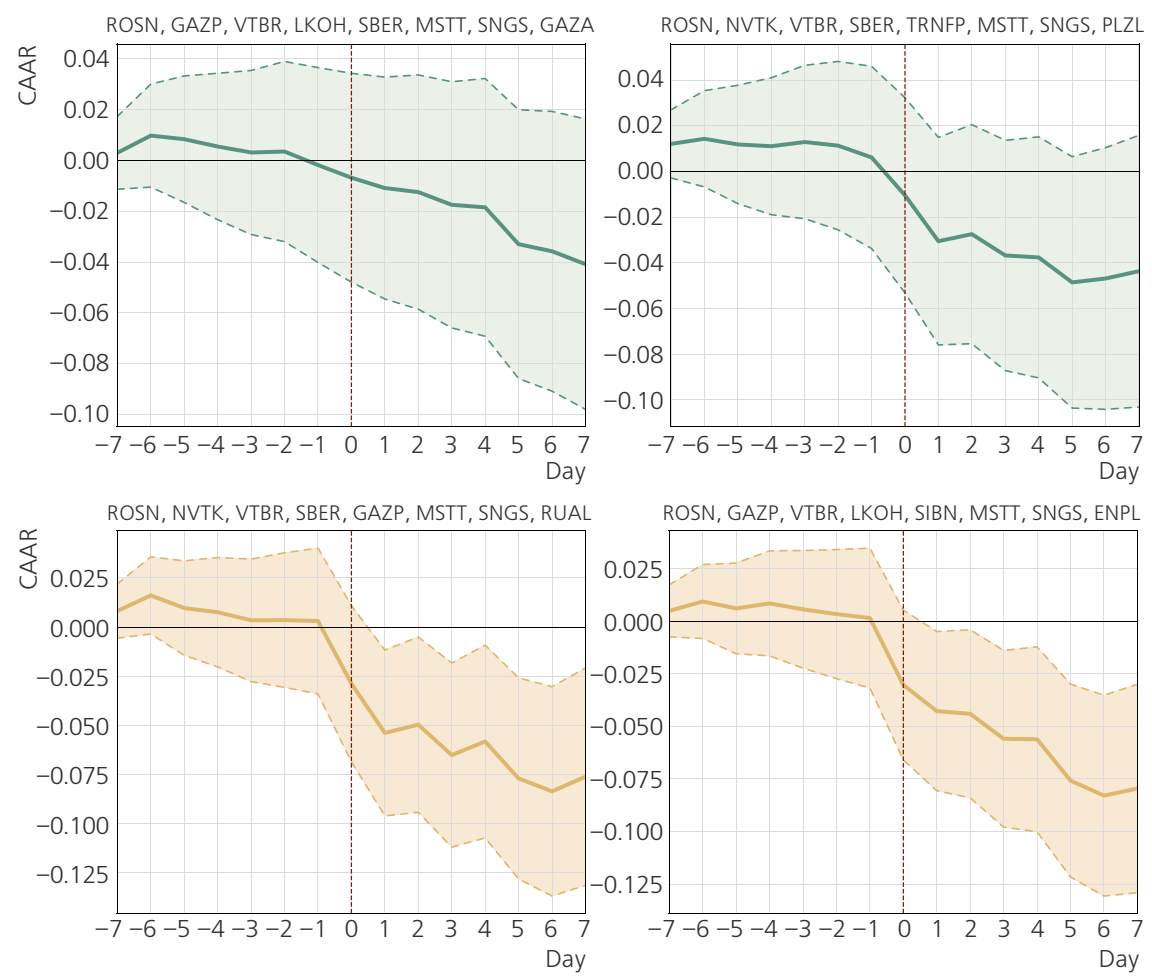

Note: event studies that have CAAR plots with yellow (green) fill colour of asymptotic CI have statistically significant (insignificant) negative CAARs after the announcement of sanctions. The market model is estimated on the basis of the MSCI EM index.

Figure 3. Average firm-specific event study of the announcement of sanctions
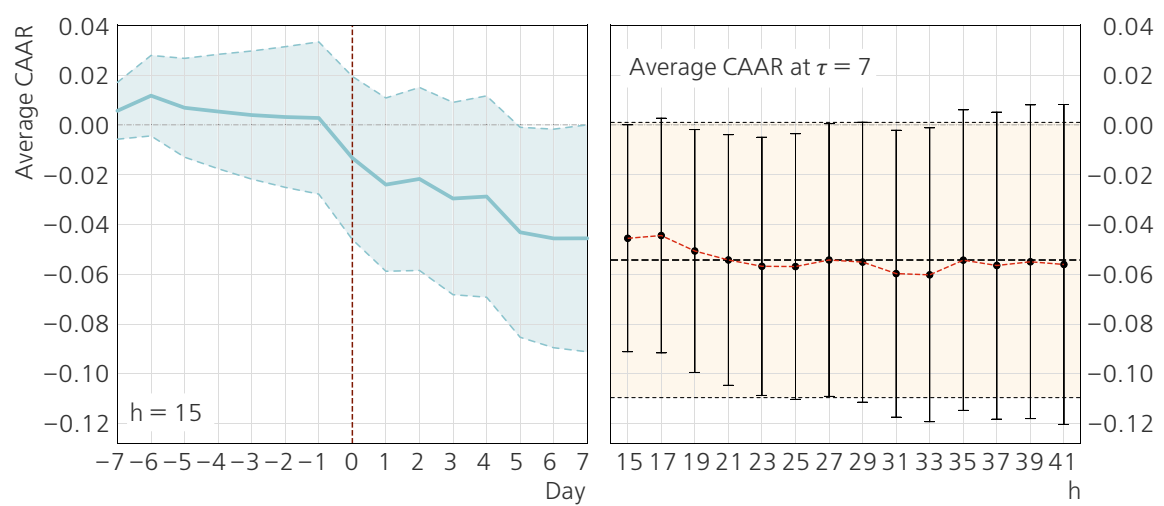

Note: the left side plots the CAAR and its CI averaged across 288 firm-specific event studies with $h=15$ (for each of the combinations of companies in Table 1). The market model is estimated on the basis of the MSCI EM index. The right side plots the CAAR and its CI on the seventh day after the sanction announcement averaged across 288 firm-specific event studies with $h \in\{15,17, \ldots, 41\}$. The black dashed line is the average estimate across different $h$ values. The black dotted lines are the averages of CI across different $h$ values. For both sides, the CIs are constructed at $10 \%$ significance. 
effect that can be identified by conducting numerous firm-specific event studies in the sample of sanction-targeted companies.

Figure 3 shows that, on average, a firm-specific event study results in a downward-sloping CAAR pattern after a typical sanction announcement. This result is consistent with intuition. Yet, if the event window's width $h$ is 15 , it appears that the result is (on average) statistically significant at $10 \%$ only in the cases of CAARs for the 5th, 6th and 7th days after the sanction announcement. For other event days, the CAARs are not (on average) statistically different from zero.

The next step is to check for robustness and examine the sensitivity of the CAAR at event day $\tau=7$ to the width of the event window $h$. The key idea is that when we increase $h$, we also increase the number of average abnormal returns that are included in the calculation of the CAAR at $\tau=7$. Intuitively, this means that the wider the event window is, the more the CAAR at $\tau=7$ takes into account the possible effect of trading based on inside information about the future sanction which took place prior to the announcement. ${ }^{6}$ Obviously, this concept will work correctly only if there are no confounding events.

The right-hand side subplot of Figure 3 presents a robustness check conducted by repeating the same 'average event study' procedure for $h \in\{15,17, \ldots, 41\}$. It demonstrates several facts. First, the estimate for the CAAR at day $\tau=7$ is rather stable for different h values, with a mean of -0.054 . Second, the CI for the CAAR at day $\tau=7$ is on average almost statistically significant at $10 \%$ for different $h$. Thus, the average estimated cumulative effect of a typical sanction announcement on the stock return of a targeted company is $-5.4 \%$ within a window of seven trading days after the announcement. On the one hand, one should be careful with this conclusion, since it was made on the basis of incorrect 'average' CIs. On the other hand, this was the only way to overcome the lack of event observations.

\subsection{Multivariate event studies}

There are two events in Table 1 to which the multivariate event study methodology can be applied: the sanction announcements on 12 September 2014 and 6 April 2018. As was discussed in Section 2, these announcements differ considerably: the former sanction was the most extensive in terms of inclusion in the SSI list, whereas the latter was the most extensive in terms of inclusion in the SDN list. Conducting multivariate event study on these two sanction announcements could answer the question of the average effects of inclusion in the SSI and SDN lists on the stock returns of a targeted company. For the purposes of robustness, I conduct both studies on the basis of the MSCI EM as well as IMOEX indices.

\footnotetext{
${ }^{6}$ By the way, this is the reason why CAARs are better estimates of the effect of sanctions than simple AARs.
} 
Figure 4. Multivariate event study for the sanction announcement of 12 September 2014, estimated CAARs of the targeted companies, $h=29$

(a) Market model: IMOEX index

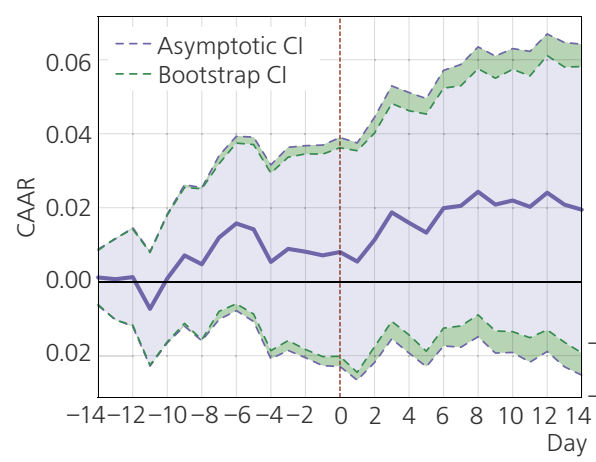

(b) Market model: MSCI ME index

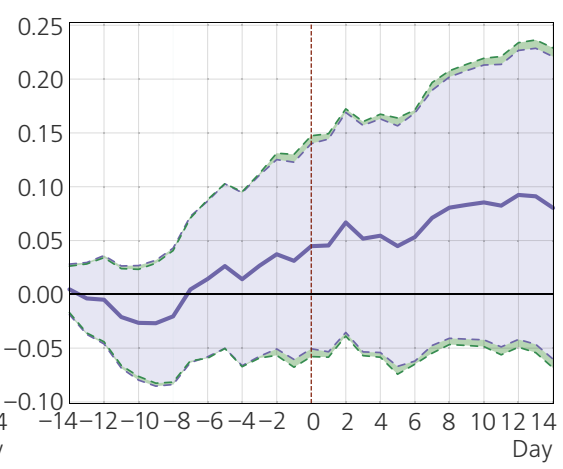

Figure 5. Multivariate event study for the sanction announcement of 6 April 2018, estimated CAARs of the targeted companies, $h=29$

(a) Market model: IMOEX index

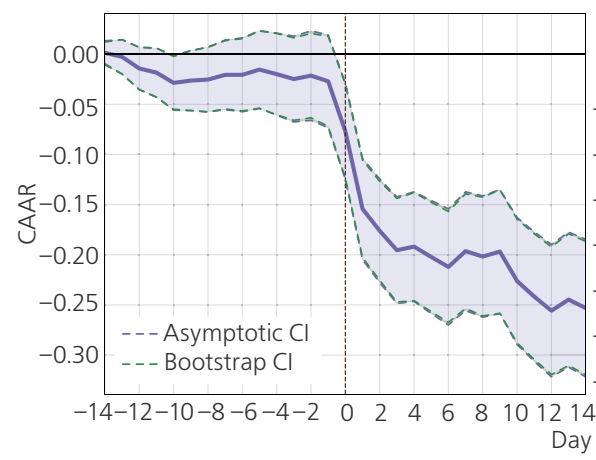

(b) Market model: MSCI ME index

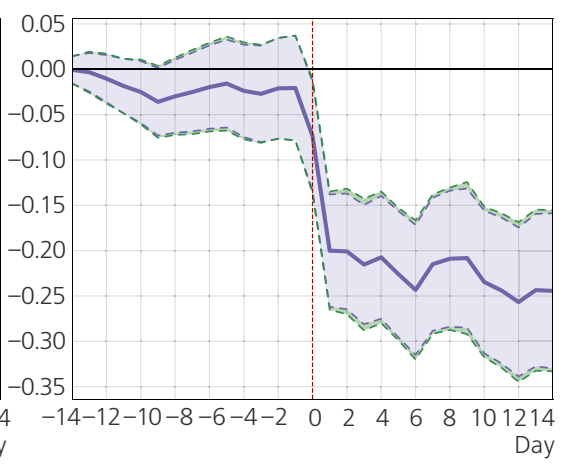

Figure 6. Multivariate event study for the sanction announcement of 6 April 2018, estimated CAARs for different sectors of the Russian economy, $h=15$

(a) Wide market

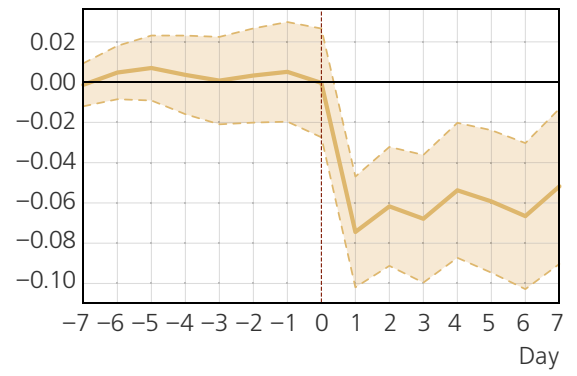

(b) Oil \& Gas

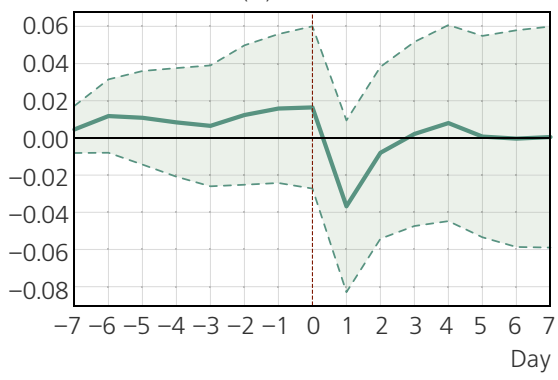

Figure 6 continued on p. 88 
(c) Power

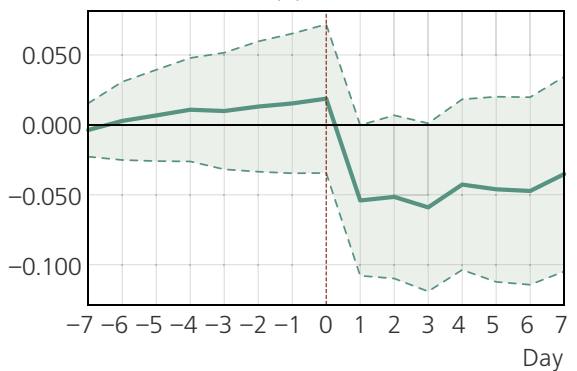

(e) Metals \& Mining

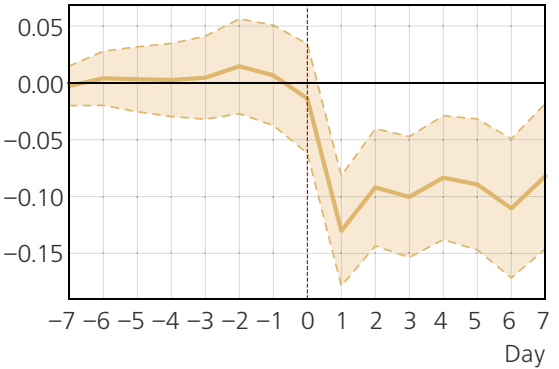

(g) Consumption

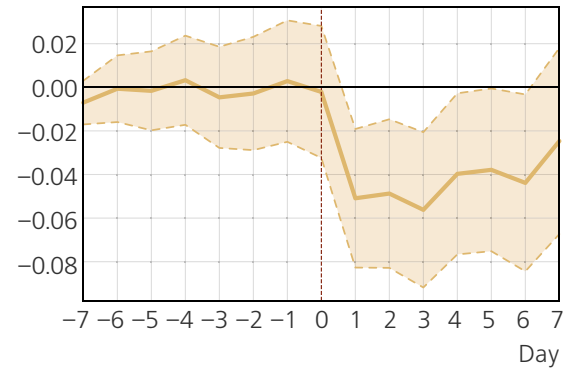

(i) Transport

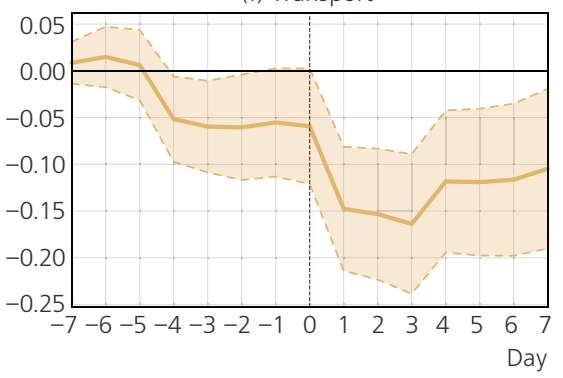

(d) Telecom

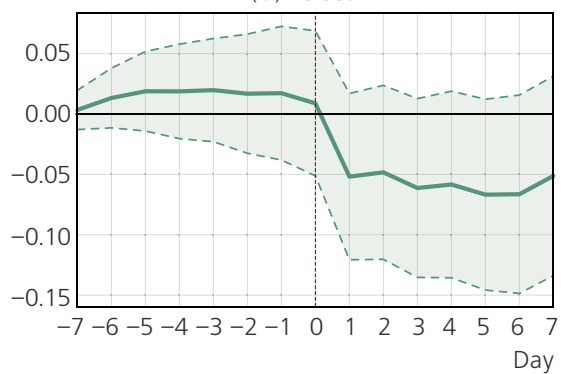

(f) Finance

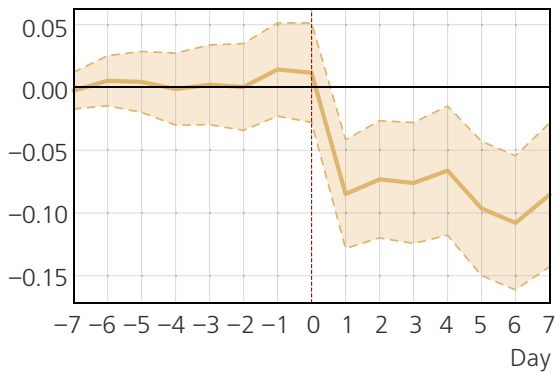

(h) Chemicals

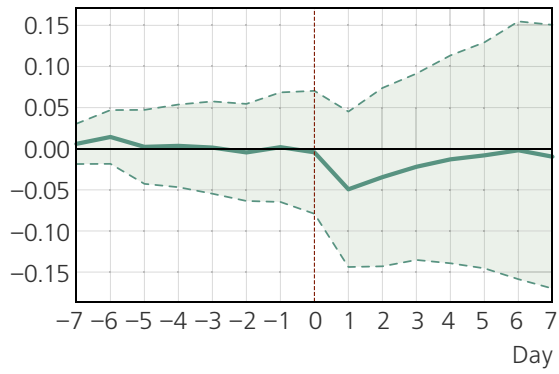

Note: due to the similarity between asymptotic and bootstrap CI, only bootstrap CI are presented. Sectors with yellow (green) fill colour of CI have statistically significant (insignificant) negative CAARs after the sanction announcement. The market model is estimated on the basis of the MSCI EM index. Samples of companies in each case are similar to the samples for the calculation of Moscow Exchange indices on 6 April 2018: (a) MICEXBMI (100 companies), (b) MICEXO and G, (c) MICEXPWR, (d) MICEXTLC, (e) MICEXM and M, (f) MICEXFNL, (g) MICEXCGS, (h) MICEXCHM, (i) MICEXTRN. 
The results for 12 September 2014 are provided in Table 2 (MSCI EM) and Table 3 (IMOEX) in Appendix D. The results for 6 April 2018 are given in Table 4 (MSCI EM) and Table 5 (IMOEX) in Appendix E. The estimates in the case of IMOEX are consistently lower than in the case of MSCI. As was mentioned in Section 3.1, this is because the IMOEX is highly correlated with the returns of targeted companies with large capitalisation. A graphical presentation of the findings can be found in Figure 4 for 12 September 2018 and Figure 5 for 6 April 2018.

The analysis shows that the sanctions that were imposed on 12 September 2014 had an insignificant effect on stock returns, whereas the impact of the sanctions announced on 6 April 2018 is substantial and equals about $20 \%$. None of the four major event study hypotheses explained and defined in Appendix C was rejected in the first case, while all were rejected with almost zero $p$-value in the second. The results may be explained as follows: (1) the SSI list is not as restrictive as the SDN list; (2) investors' negative expectations about the scale of the upcoming sanctions were not eventually justified on 12 September 2014; (3) investors underestimated the scale of the future sanctions prior to 6 April 2018 and were caught off guard.

Multivariate event studies are also useful for estimating the effect of a sanction announcement on the market as a whole and on its different sectors separately. Figure 6 graphically presents the results for 6 April 2018 (see also Figure 11 for $h=29$ in Appendix E). Figure 10 represents the reaction of the market on 12 September 2014 (Appendix D). On 12 September 2014, the pattern of CAARs is insignificantly positive for the wide market and for each of the sectors, except for Oil and Gas, where returns are positive. When it comes to 6 April 2018, the analysis shows that the greatest negative impact was made on such sectors as metals and mining, finance, consumption and transport.

One of the standard problems in financial econometrics is that sometimes the estimate of $\beta$ in the market model appears to be sensitive to the choice of the estimation window. Thus, the results of an event study can potentially depend on the width of the estimation window $l$ (see Appendix $C$ ). Moreover, the results can also differ depending on the choice of $h$, the width of the event window. In order to check that the result of the multivariate event study for 6 April 2018 is robust to the choice of $l$ and $h$, I conducted calculations for $l \in\{150,200,250,300\}$ and $h \in\{11,13,15, \ldots, 41\}$. The results for the CAAR at days $\tau=1$ (right after the sanction announcement) are summarised in Figure 7. In Appendix E, Figure 12 presents similar results for $\tau=5$. In both cases, the estimates prove to be more sensitive to changes in $h$ than to changes in $l$. This is logical, because the wider the event window is, the more abnormal returns are included in the calculation of CAARs. Moreover, with higher $h$, the bootstrap CIs become wider, since they account for the variation in the larger number of the previous abnormal returns. Overall, the robustness check demonstrates that the optimal choice for $h$ is 23, 
because it ensures that the estimates of the CAARs are almost identical to the averages of the estimates across different $h$ values.

Figure 7. Robustness check for the CAAR right after the sanction announcement $(\tau=1)$
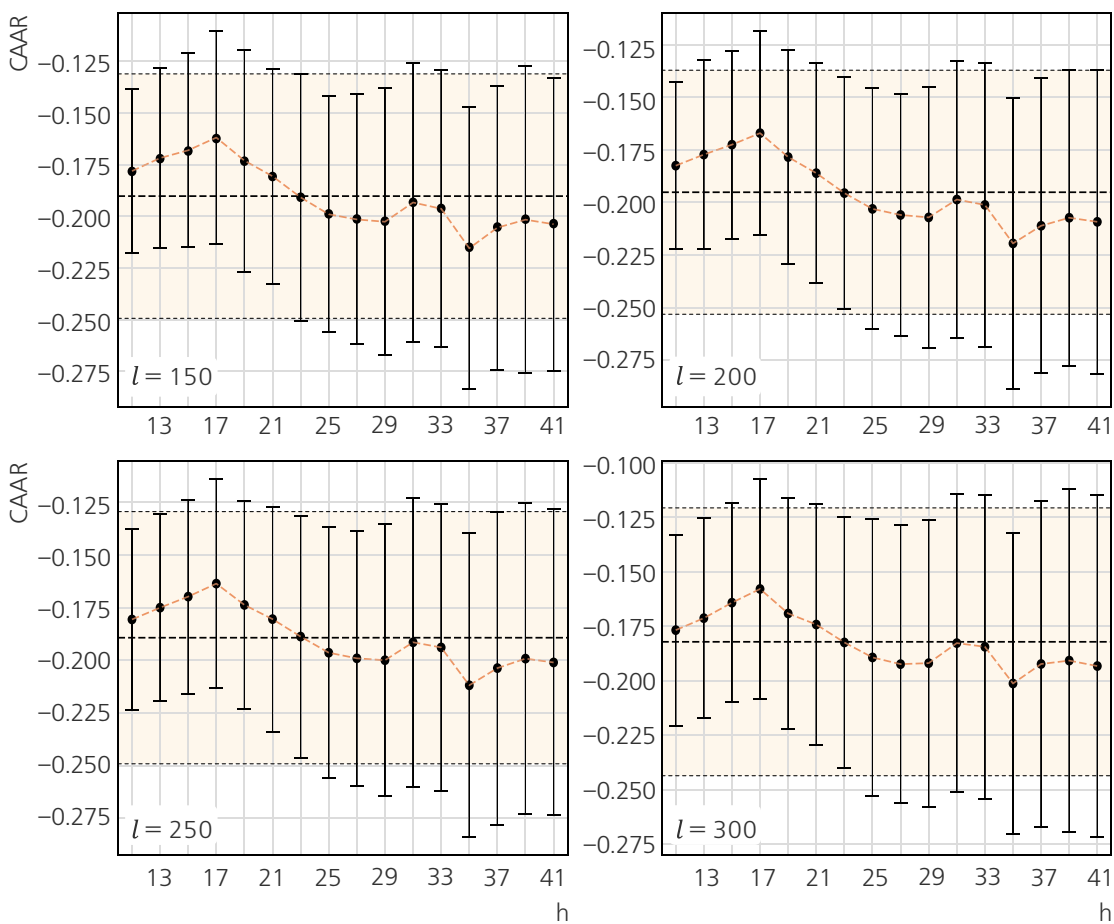

Note: CAARs from the beginning of the event window up to the 1st day after the sanction announcement are calculated for different event $(h)$ and estimation $(l)$ windows. The market model is based on the MSCI EM index. Bootstrap CIs at $5 \%$ significance for each CAAR are plotted as the vertical lines with dashes on the ends. The horizontal black dashed line represents the average value of the CAAR for different $h$ values. The horizontal black dotted lines represent the averages of the CIs.

\section{Conclusion}

On the basis of firm-specific event study of eight sanction announcements targeting 14 entities at different times, the following conclusion is made. On average, the announcement of the imposition of a sanction that targets a Russian public company has a negative impact on its equity returns. The average effect is measured as the estimate of the expected cumulative abnormal return within a window of seven trading days after the announcement of sanctions and amounts to $-5.4 \%$. The estimate can be considered as statistically significant at the $10 \%$ level. At the same time, one should take into the account that this result depends crucially on the presence of the 6 April 2018 sanction announcement in the sample of events. Without this data, the statistical significance of the results would be much lower. 
Multivariate event study analysis of the two most extensive sanctions imposed by the US on the Russian economy, on 12 September 2014 and on 6 April 2018, shows that the effect of the announcement of the former was statistically equal to zero, whereas for the latter, estimates of the expected cumulative abnormal return already on the 5th day after the announcement are steadily around $-20 \%$. On the one hand, this result indicates the failure (in the context of equity markets) of sectoral sanctions, which were designed specifically to restrict the foreign financing of large-cap state-affiliate Russian public companies. On the other hand, the result demonstrates the effectiveness of the standard time-tested OFAC procedure of inclusion in the SDN list.

When it comes to areas for further research, it would be of substantial scientific interest to investigate the immediate intra-day reaction of the market to the announcement of sanctions. The complete list of sanctions described in Section 3.2 contains the exact time (down to the minute) of each of the announcements, and the Moscow Exchange Type B data set covers all intra-day transactions, which makes it possible to do such research in the framework of the market microstructure theory.

\section{Appendices are available at \\ http://rjmf.econs.online/en; \\ dx.doi.org/10.31477/rjmf.202001.74}

\section{References}

Anatolyev, S. (2007). The Basics of Bootstrapping. Quantile, 3, pp. 1-2. [In Russian]. Available at: http://www.quantile.ru/03/03-SA.pdf [accessed on 28 December 2019].

Ankudinov, A., Ibragimov, R. and Lebedev, O. (2017). Sanctions and the Russian Stock Market. Research in International Business and Finance, 40, pp. 150-162.

Binder, J. J. (1985). On the Use of the Multivariate Regression Model in Event Studies. Journal of Accounting Research, 23(1), pp. 370-383.

Campbell, J. Y., Lo, A. W. and MacKinlay, A. C. (1997). The Econometrics of Financial Markets, Vol. 2. Princeton, NJ: Princeton University Press.

Chou, P.-H. (2004). Bootstrap Tests for Multivariate Event Studies. Review of Quantitative Finance and Accounting, 23(3), pp. 275-290.

Dreger, C., Kholodilin, K. A., Ulbricht, D. and Fidrmuc, J. (2016). Between the Hammer and the Anvil: The Impact of Economic Sanctions and Oil Prices on Russia's Ruble. Journal of Comparative Economics, 44(2), pp. 295-308.

Fama, E. F., Fisher, L., Jensen, M. C. and Roll, R. (1969). The Adjustment of Stock Prices to New Information. International Economic Review, 10(1), pp. 1-21.

Galtung, J. (1967). On the Effects of International Economic Sanctions, with Examples from the Case of Rhodesia. World Politics, 19(3), pp. 378-416.

Gurvich, E. and Prilepskiy, I. (2016). The Impact of Financial Sanctions on the Russian Economy. Voprosy Economiki, 1, pp. 5-35. [In Russian].

doi: 10.32609/0042-8736-2016-1-5-35 
Hein, S. E. and Westfall, P. (2004). Improving Tests of Abnormal Returns by Bootstrapping the Multivariate Regression Model with Event Parameters. Journal of Financial Econometrics, 2(3), pp. 451-471. doi: 10.1093/jjfinec/nbh018

Hufbauer, G. C., Schott, J. J. and Elliott, K. A. (1990). Economic Sanctions Reconsidered: History and Current Policy, Vol. 1. Washington, DC: Peterson Institute.

Kholodilin, K. A. and Netšunajev, A. (2019). Crimea and Punishment: The Impact of Sanctions on Russian Economy and Economies of the Euro Area. Baltic Journal of Economics, 19(1), pp. 39-51.

Kirshner, J. (1997). The Microfoundations of Economic Sanctions. Security Studies, 6(3), pp. 32-64.

Kothari, S. and Warner, J. B. (2007). Econometrics of Event Studies. In: B. E. Eckbo, ed., Handbook of Corporate Finance: Empirical Corporate Finance, Vol. 1. Elsevier, pp. 3-36.

Lefebvre, J. (2007). The Bootstrap in Event Study Methodology. M. Sc. Thesis, Universite de Montréal. Available at: https://papyrus.bib.umontreal.ca/xmlui/handle/1866/1503 [accessed on 28 December 2019].

Naidenova, J. and Novikova, A. (2018). The Reaction of Russian Public Companies' Stock Prices to Sanctions against Russia. Journal of Corporate Finance Research, 12(3), pp. 27-38.

Nivorozhkin, E. and Castagneto-Gissey, G. (2016). Russian Stock Market in the Aftermath of the Ukrainian Crisis. Russian Journal of Economics, 2(1), pp. 23-40.

Zarate, J. (2013). Treasury's War: The Unleashing of a New Era of Financial Warfare. London, UK: Hachette. 